\title{
The Extent of the Challenges in Online Learning during the COVID-19 Pandemic
}

\author{
Reynaldo Abrea Cabual'1, Ma. Minisa Aquino Cabual ${ }^{2}$ \\ ${ }^{1}$ College of Education/Graduate School, Nueva Ecija University of Science and Technology, Cabanatuan, Philippines \\ ${ }^{2}$ Honorato C. Perez, Sr. Memorial Science High School, Department of Education, Cabanatuan City Division, Philippines \\ Email:racabual50@gmail.com,maminisa.cabual@deped.gov.ph
}

How to cite this paper: Cabual, R.A. and Cabual, Ma.M.A. (2022) The Extent of the Challenges in Online Learning during the COVID-19 Pandemic. Open Access Library Journal, 9: e8233.

https://doi.org/10.4236/oalib.1108233

Received: November 26, 2021

Accepted: January 17, 2022

Published: January 20, 2022

Copyright $\odot 2022$ by author(s) and Open Access Library Inc.

This work is licensed under the Creative Commons Attribution International License (CC BY 4.0).

http://creativecommons.org/licenses/by/4.0/ (c) (i) Open Access

\begin{abstract}
The study aimed at identifying the profile of the respondents and the challenges in online learning during the COVID-19 Pandemic experienced by the students in the College of Education at the Nueva Ecija University of Science and Technology during the first semester of the academic year 2020-2021. The identified challenges were slow internet connectivity; using data only; gadget used; noise environmental/surroundings/distractions; financial/budget considerations; technical issues; lack of in-person interaction; understanding course expectations; time management; staying motivated; and uncertainty about the future. The 299 students were asked to accomplish a customized questionnaire prepared by the researchers to get the profile variables and the challenges encountered during the COVID-19 Pandemic through "google forms." Only 212 responded due to their limitations. The responses were downloaded from the google forms in the spreadsheet format. The quantitative and qualitative methods were used in analyzing and interpreting the data. Most respondents are Bachelor of Technology and Livelihood Education students. They are first-year females and fall within 20 years old and below. All the identified challenges were verbally described as "Very High Extent." The students' topmost challenges were noise/environmental distractions, technical issues, and slow internet connection. Course expectations and uncertainly about the future were the minor challenges in online learning during the COVID-19 Pandemic. The challenge on "staying motivated" is significantly correlated with their "course", and "used data only" with their age and year-level. Although, the overall result shows no significant relationship between the profiles of the respondents and the challenges in online learning. There should be a student's needs assessment on internet connection and equipment needed to meet the demands of the online classes before the opening of classes. Alternative delivery of instruction must be prioritized, students must be allowed to practice their skills, free themselves from the noise/environmental distractions, free-webinar lecture on troubleshooting
\end{abstract}


technical issues they experienced in online learning, and a review and revision of the syllabus of instruction should be prioritized.

\section{Subject Areas}

Sociology and Psychology

\section{Keywords}

Challenges, Online Learning, COVID-19, Pandemic

\section{Introduction}

Due to students' frequent needs, desires, and requirements, the academic world remains in flux. Thus, computer technology and distance education are seen as critical components in assisting colleges in completing their different assignments. Nonetheless, colleges face a critical task in the era of technology: incorporating innovative e-learning tools to enhance teaching and learning.

Due to its scope, E-learning has a limited number of terms. To put it simply, it entails the use of science, computational technologies, and programs to build and design learning environments (Horton, 2006) [1]. E-learning incorporates distance learning and teaching using digital platforms defined by the internet, CD-ROMs, mobile phones, and even television. In a nutshell, the concept of e-learning is better understood in terms of how technology is used to meet people's desire to learn and improve. As a consequence of the multitude of opportunities available today, there are many ways of E-learning. Horton defined three categories of lessons: individual courses, which students take without the presence of peers; interactive classes, which are organized similarly to face-to-face courses; and learning games, in which the task of interpreting and assimilating knowledge is accomplished by simulation experiences.

According to one interpretation, the term "e-learning" was first introduced to education in the mid-1990s. By connecting the above concepts, it can be seen as a functional extension of the distance learning theory (Sangra, et al., 2011) [2].

According to a detailed overview, e-learning is just another means of describing teaching and learning. Technological resources and mediums assist in promoting development and improving the quality of schooling and training. Electronic services provide knowledge to a large audience through an e-learning process. These systems need computers and the internet to operate.

Numerous facets of E-learning contribute to and sustain the learning-teaching process. Downloading does not include additional resources, and once submitted, the content remains available to users (Raheem \& Khan, 2020) [3].

As a result, e-learning needs technical infrastructure and technology and e-learning platforms, content, and participants (Cohen, 2006) [4].

E-learning differs from traditional or other modes of education in that it is, according to Oye, Salleh, \& Iahad [5], customized. While conventional education 
places a premium on the instructor, E-learning places a greater emphasis on the pupil.

Assessments, studies, and scholarly sources are often used to distinguish between traditional and online schooling. While students in formal education are evaluated solely by teachers, who often serve as their primary source of information, and the quality of education is dependent on teachers' knowledge and skills, in online learning, students may obtain information from a variety of documents uploaded to the platform. Teachers' skills and knowledge in using technology are also factors that influence the quality of education. Cheung and Cable [6] defined and outlined eight fundamental concepts of successful online teaching, including the following: promoting communication between students and faculty, interactive learning, quick input, constructive learning, work time, enabling students to dedicate additional time to assignments, high aspirations, and diverse learning (Babu \& Sridevi) [7].

\section{Research Questions}

Generally, the study aimed at identifying the profile of the respondents and the challenges in online learning during the COVID-19 Pandemic experienced by the students in the College of Education at the Nueva Ecija University of Science and Technology during the first semester of the academic year 2020-2021.

Specifically, the following questions were answered:

1) How may the profile of the student-respondents be described in terms of:

a) age:

b) sex; and

c) field of specialization/course?

2) How may the extent of the challenges in online learning during the COVID-19 Pandemic be described in terms of:
a) slow internet connectivity;
b) using data only;
c) gadget used;
d) noise environmental/surroundings/distractions;
e) financial/budget considerations;
f) technical issues;
g) lack of in-person interaction;
h) understanding course expectations;
i) time-management;
j) staying motivated: and
k) uncertainty about the future?
3) Is there a significant relationship between the respondents' extent of the challenges in online learning during the COVID-19 Pandemic and their profiles in terms of age, sex, year level, and course?

\section{Methodology}

The quantitative and qualitative methods to solicit the responses of the respon- 
dents were used.

Fellows and Liu (2008) [8] said that quantitative research methods are usually adopted because they are scientific methods and provide immediate results. Another reason behind selecting this approach is that it is more efficient, can test hypotheses, and always targets clarifying features, matter them, and build statistical models to describe what is discovered during research. According to Matthews and Ross (2010) [9], quantitative research methods are fundamentally put on collecting data set up, which could be displayed numerically. Generally, quantitative data is accumulated when a researcher has followed the positivist epistemological way and data are collected that may be scientifically analyzed.

In this study, the profile of the students and their challenges in online learning under the COVID-19 Pandemic were treated qualitatively and quantitatively. The questionnaire was sent to the students through google forms, for it is still pandemic and the safety of the students is the topmost priority. It consisted of the profile of the students in terms of age, sex, and field of specialization. The second part included the challenges on slow internet connectivity, using data only, gadgets used, noise environmental/surroundings/distractions, financial/budget considerations, technical issues, lack of in-person interaction, understanding course expectations, time-management, staying motivated, and uncertainty about the future.

The 292 students were instructed to complete the sets of questions sent through Google Forms. They have ten days to complete the survey. Due to difficulties with internet access and the fact that several students utilized just their smartphones, only 212 students responded to the survey. Apart from the fact that it is still pandemic, it has a 72.6 percent efficiency rate.

A test of relationships using Spearman rho was used to determine if there is a significant relationship between the extent of the challenges in online learning and their course, year-level, sex, and age profiles.

The qualitative analysis, a non-numerical data collection approach focused on empirical observation, was also used to analyze the relationship of the profiles of the students and the challenges they encountered, particularly on the profile variables on course, year-level, sex, and age.

Qualitative research is mainly found in disciplines where the target is on reason and information such as sociology, interpersonal anthropology, and psychology rather than predictions Hakim (2010) [10]. This is appropriately applicable because it is pandemic time. Bryman and Bell (2007) [11] explained that qualitative research is a study strategy that implies the relationship between theory and research and usually emphasizes how theories were made. Qualitative research is inductivist, constructionist, and interpretivist, but qualitative researchers do not subscribe to all three of these methods.

\section{Results and Discussions}

The following tables show the survey results regarding the student's challenges 
during the COVID-19 Pandemic at the College of Education in the Nueva Ecija University of Science and Technology. This part includes the students' profile, the student's challenges, and the results of the test of significant relationships on the student's profile and their challenges encountered in online learning under the COVID-19 Pandemic. This portion includes the age, sex, year-level, and course of the students presented in Tables 1-3.

\subsection{Profile of the Respondents}

A total of 292 first and second-year students in the Bachelor of Technology and Livelihood and Bachelor of Science in Industrial Education were enrolled in the second semester of the academic year 2020-2021. The college employed asynchronous and synchronous classes due to the COVID-19 Pandemic. After the final examination, they were requested to answer the challenges they encountered in online learning for the two semesters. The combined students who participated in the survey were 212 after the 10 day-period provided to them. This was done via google forms.

Table 1 shows the distribution of the student-respondents as to their course and year-level.

From the total 212 respondents, there are 126 (59.40\%) Bachelor of Technology and Livelihood Education (BTLEd), and 86 (40.60\%) from the Bachelor of Science in Industrial Education (BSIE) who participated in the survey.

It can be deduced that more students enrolled in the BTLEd program than the BSIE program. This situation can be attributed to the fact that there are a variety of opportunities if a student is a graduate of BTLEd program. Almost all schools, be it a private or a public school is offering the Home Economics and Livelihood Education in the Philippines and even other ASEAN countries.

The distribution of the respondents as to year-level is presented in Table 2.

From Table 2, it can be viewed that the combined 212 BTLEd and BSIE student-respondents were distributed as first and second-year. There are 116 (54.70\%) first-year students and 96 (45.30\%) who participated in the survey.

Table 1. Distribution of respondents as to course.

\begin{tabular}{ccc}
\hline Course & Frequency & Percent \\
\hline BTLEd & 126 & 59.40 \\
BSIE & 86 & 40.60 \\
Total & 212 & 100.0 \\
\hline
\end{tabular}

Table 2. Distribution of respondents as to year-level.

\begin{tabular}{ccc}
\hline Year Level & Frequency & Percent \\
\hline First Year & 116 & 54.70 \\
Second Year & 96 & 45.30 \\
Total & 212 & 100.0 \\
\hline
\end{tabular}


The findings revealed that more first-year students responded to the survey evidently. It can be said somehow that they are more interested and have more time to take the quick survey. The first-year students are more expressive in presenting their views and opinions with the hope of change in their professors' delivery modes of instruction. Their course is a skill-based course that requires more face-to-face interactions with professors and classmates.

Table 3 presents the distribution of the student-respondent's sex and age profiles.

The students' sex and age profiles are shown in Table 3. From the combined 212 BTLEd and BSIE students, the majority are females, 183 or $86.30 \%$, while there are only 29 or $13.70 \%$ males. The majority of the students' age falls within 20 and below with 182 or $85.85 \%$, followed by 21 - 24 year-old bracket with 27 or $12.74 \%$, and 25 and above with three or $1.41 \%$.

Surprisingly, more females are attracted to BTLEd and BSIE programs, although these are skilled courses. They are young, under age 20 and below. As Cabual, R.A. (2021) [12] mentioned in his study on the Learning Styles and the Preferred Learning Modalities in the New Normal, age is not a factor in learning. He added that a person's career might be pursued regardless of one's age, as in the three respondents in the present study who are 25 and above years old. The age of the students who are second-year college supposedly falls within $20-22$ years old only.

\subsection{Extent of the Challenges in Online Learning during the COVID-19 Pandemic}

The challenges of the students in online learning during the COVID-19 Pandemic have been identified in the entire college. Some of them, are also a product of the personal experiences of the researchers in their respective schools.

Table 4 shows the extent of the challenges in online learning during the COVID-19 Pandemic.

It can be gleaned from the table that all the identified challenges in online learning during the COVID-19 Pandemic have an overall average weighted mean of 3.27, verbally described as "Very High Extent."

If analyzed per item, item \# 4 (noise/environment distraction) has the highest weighted mean of 3.58, followed by item \# 6 (technical issues) with 3.46, and item \# 1 (slow internet connection) with 3.41 , verbally described as "Very High Extent", respectively.

Table 3. Distribution of the respondents as to sex and age.

\begin{tabular}{cccccc}
\hline Sex & Frequency & Percent & Age & Frequency & Percent \\
\hline Male & 29 & 13.70 & 20 and Below & 182 & 85.85 \\
Female & 183 & 86.30 & $21-24$ & 27 & 12.74 \\
Total & 212 & 100.0 & 25 and above & 3 & 01.41 \\
& & & Total & 212 & 100.00 \\
\hline
\end{tabular}


Table 4. Extent of the challenges in online learning during the COVID-19 Pandemic.

\begin{tabular}{lcc}
\hline \multicolumn{1}{c}{ Challenges in Online Learning } & Weighted Mean & Verbal Description \\
\hline 1. Slow internet connection & 3.41 & Very High Extent \\
2. Used data only & 3.17 & High Extent \\
3. Gadget used & 3.17 & High Extent \\
4. Noise/environmental distractions & 3.58 & Very High Extent \\
5. Financial/budget consideration & 3.29 & High Extent \\
6. Technical issues & 3.46 & Very High Extent \\
7. Lack in-person interaction & 3.19 & High Extent \\
8. Course expectations & 3.13 & High Extent \\
9. Time management & 3.19 & High Extent \\
10. Staying motivated & 3.18 & High Extent \\
11. Uncertainty about the future & 3.14 & High Extent \\
Average Weighted Mean & 3.27 & Very High Extent \\
\hline
\end{tabular}

Other identified challenges are verbally described as "High Extent", such as item \# 2 "used data only", item \# 3 "gadget used", item \# 5 "financial/budget consideration", item \# 7 "lack-in person interaction", item \# 8 "course expectations", item \# 9 "time management", item \# 10 "staying motivated", and item \# 11 "uncertainty about the future." But item \# 8 "course expectations," and item \# 11 "uncertainty about the future," has the lowest weighted mean of 3.13 and 3.14 , respectively.

These findings implied that the students are challenged about the noise/environmental distractions, technical issues, and slow internet connection. Since classes were held via the online platforms, the students in their respective homes were greatly affected by the noise/environmental distractions that may be caused by their neighborhood. Their respective family members were also felt affecting the students' studies, especially if there are children playing for they are living within a small house.

If the students are living in a rural area, the noise/environment distractions were attributed to the means of living of the neighborhood. Most of the industries in the rural areas are in poultry, piggery, hog raising and the like that cause of lot of noise/environmental distractions when the students attended to their online classes.

The technical issues also posed a very high extent challenge to the students, especially if they are not knowledgeable about fixing their computers, laptops, gadget used, and the like. Further, if there are no available service providers in their hometown, they need to travel to the city or malls to have their things fixed. Slow internet connection challenged a lot to the students aside from the use of data only for them to attend to their online learning. Some students dropped off their connections while in their online classes. When they tried to reconnect, they usually 
found it difficult to join the class again. This is one of the utmost problems students and teachers alike experience in the conduct of online learning.

The $2^{\text {nd }}$ Quarter report supports the above findings. It was observed that there was a $1.0 \%$ quarterly decrease in global internet connectivity. The global average connection speed decreased 2.3\% to $6.1 \mathrm{Mbps}$ from 6.3 Mbps, while the average peak connection speed increased $3.7 \%$ to $36.0 \mathrm{Mbps}$ from 34.7. Mobile data traffic grew by $11 \%$ over the previous quarter. Each quarter, Akamai publishes the State of the Internet Report based on their Akamai Intelligent Platform.

The Philippines hopes to enjoy faster speeds soon, as the two major network service providers in the country (Smart-PLDT and Globe Telecom) announced in the second quarter, the purchase of the $700 \mathrm{MHz}$ frequency from SMC that is expected to enable faster Internet service speeds at lower costs, albeit for the wireless (mobile) connectivity.

Further, the Information and Communications Technology (ICT) Secretary Gregorio Honasan (2020) [13] stated the Department of Information and Communications Technology would continue to coordinate with the National Telecommunications Commission (NTC) to help ensure that the telco's roll-out plans are complied with on time. He added that the vision of digital transformation should be realized if all Filipinos, regardless of who they are and where they are in the country, have quality access to Internet connectivity services at affordable prices (February 20, 2021).

Added to the findings is that the students are not much affected by course expectations and uncertainty about the future. When they decide to enroll in the BTLEd and BSIE courses, they are assured that they will land a job after graduation. Some of their opportunities are to be Technology and Livelihood Teacher, Assistant Teacher, Livelihood Program Facilitator, Community Project Organizer, Researcher, and Tutor. Furthermore, individual cognitive constructivism has grown out of the foundational work of Jean Piaget [14] and is a theory that views the learner as agentic (i.e., the ability of an individual to make choices and act on those choices) and learning as an active process of individual meaning-making. Examples of cognitive constructivist methods include active learning, problem-based learning, and inquiry learning (Kirschner, Sweller, and Clark (2006) [15]. Learner interactions with course content in particular, frequently occurred at an individual level in the online learning contexts.

It is also supported by Ane, T. and Nepa, T. (2021) [16], in their study on Statistical Survey of Students' Performance: Online Education to COVID-19 in Bangladesh. It revealed that students strongly agree that class lecture videos are supportive (47.2\%) and (13.1\%) highly appreciate online exam evaluation but (63.6\%) accepted online evaluation policy with different opinions. It has shown students think sometimes technological and essential supports are not available with online education (95.3\%) and minor cases feel it has well designed online support while they are dissatisfied (44.3\%) with lab inefficiency and they put effective suggestions for improving laboratory facilities during lockdown classes. There were also indications that some students were not able to use laboratory 
accessories. So, they were too late to complete lab task and sometime wait others student to get assignment done and then can access their computers or laptops.

At par with the BTLEd and BSIE students, they preferred to have a face-to-face class so that they can master the needed skills required for their programs.

\subsection{Relationship of the Students' Profile variables with Their Challenges in Online Learning}

Table 5 presents the relationships between the extent of the challenges in online learning and their profiles when grouped according to course, year-level, sex, and age.

The analysis demonstrates that profile variables such as course, year level, and age resulted in Spearman rho values indicating a significant relationship level with the presented challenges. "Course and staying motivated" have a correlation coefficient of -0.137 , indicating a significance level of 0.046 ; "year level" and "used data only" have a correlation coefficient of 0.144 , indicating a significance level of 0.037; and "age" has correlation coefficients significant to two challenges, "used data only" (0.263) and "financial/budget considerations" (0.138), respectively, at 0.000 and 0.044 .

In terms of negative correlation, the higher the year level, the smaller the scope of their challenges become. However, due to the proportions of those profile

Table 5. Relationship between the profile of the students and their challenges in online learning.

\begin{tabular}{|c|c|c|c|c|c|c|c|c|c|c|c|c|}
\hline 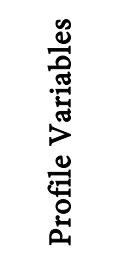 & 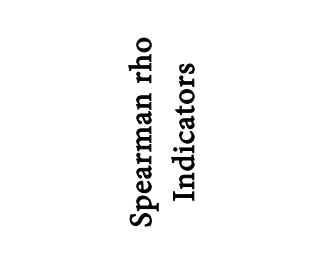 & 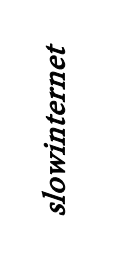 & 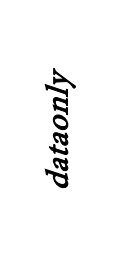 & $\begin{array}{l}7 \\
8 \\
3 \\
3 \\
5 \\
0 \\
0 \\
0 \\
0\end{array}$ & 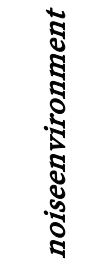 & 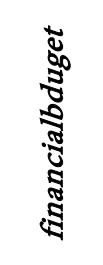 & 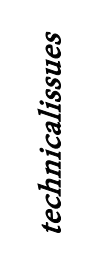 & 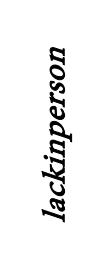 & 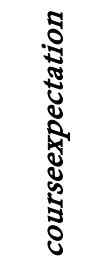 & 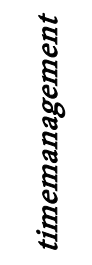 & 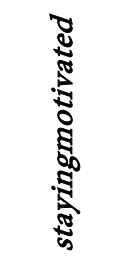 & 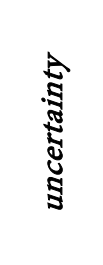 \\
\hline \multirow{3}{*}{ Course } & Correlation Coefficient & -0.006 & 0.013 & -0.006 & -0.024 & 0.077 & 0.035 & 0.004 & 0.125 & 0.049 & $-0.137^{\star}$ & 0.026 \\
\hline & Sig. (2-tailed) & 0.928 & 0.854 & 0.930 & 0.732 & 0.267 & 0.612 & 0.951 & 0.070 & 0.482 & 0.046 & 0.706 \\
\hline & $\mathrm{N}$ & 212 & 212 & 212 & 212 & 212 & 212 & 212 & 212 & 212 & 212 & 212 \\
\hline \multirow{3}{*}{$\begin{array}{c}\text { Year } \\
\text { Level }\end{array}$} & Correlation Coefficient & -0.024 & $0.144^{*}$ & -0.124 & -0.018 & 0.000 & -0.090 & 0.086 & 0.017 & 0.099 & 0.084 & 0.071 \\
\hline & Sig. (2-tailed) & 0.724 & 0.037 & 0.072 & 0.799 & 0.999 & 0.193 & 0.213 & 0.811 & 0.152 & 0.223 & 0.306 \\
\hline & $\mathrm{N}$ & 212 & 212 & 212 & 212 & 212 & 212 & 212 & 212 & 212 & 212 & 212 \\
\hline \multirow{3}{*}{ Sex } & Correlation Coefficient & -0.030 & -0.034 & -0.102 & -0.033 & -0.006 & 0.027 & -0.016 & 0.075 & 0.084 & 0.076 & -0.009 \\
\hline & Sig. (2-tailed) & 0.665 & 0.618 & 0.140 & 0.633 & 0.934 & 0.697 & 0.820 & 0.275 & 0.223 & 0.273 & 0.895 \\
\hline & $\mathrm{N}$ & 212 & 212 & 212 & 212 & 212 & ,212 & 212 & 212 & 212 & 212 & 212 \\
\hline \multirow{3}{*}{ Age } & Correlation Coefficient & 0.018 & $0.263^{\star *}$ & 0.034 & 0.020 & $0.138^{*}$ & -0.068 & 0.062 & -0.007 & 0.127 & -0.004 & 0.108 \\
\hline & Sig. (2-tailed) & 0.799 & 0.000 & 0.622 & 0.774 & 0.044 & 0.322 & 0.372 & 0.917 & 0.064 & 0.950 & 0.118 \\
\hline & $\mathrm{N}$ & 212 & 212 & 212 & 212 & 212 & 212 & 212 & 212 & 212 & 212 & 212 \\
\hline
\end{tabular}

${ }^{*}$ Correlation is significant at the 0.01 level (2-tailed). ${ }^{\star}$ Correlation is significant at the 0.05 level (2-tailed). 
variables discovered to be significantly associated with challenges, the researchers were unable to reject the formulated hypothesis. As a result, there is no quantifiable relationship between the respondents' demographic characteristics and their challenges.

Among the challenges identified, "staying motivated" is significantly correlated with their "course" and "used data only" with their age and year-level.

The results can be attributed to the self-directed attitude of the students toward their studies. The moment they entered college and preferred the BTLEd and BSIE courses have put themselves into the situation that no matter what happens, they need to embrace the challenges that will come along the way in their journey as students and as individuals. According to Paris and Turner (1994) [17], motivation is the "engine" of learning. Motivation can influence what one learns, how one learns, and when one chooses to learn (Schunk and Usher, 2012) [18]. Research shows that motivated learners are more likely to undertake challenging activities, be actively engaged, enjoy and adopt a deep approach to learning and exhibit enhanced performance, persistence, and creativity (Ryan and Deci, 2000b) [19]. Given the important reciprocal relationship between motivation and learning (Brophy, 2010) [20], it is not surprising that motivation has been actively researched across a wide range of traditional educational settings (Schunk and Pintrich, 2014) [21]. Despite this, studies that explore motivation to learn in online contexts are limited in both number and scope, as others have noted (Bekele, 2010) [22].

The challenge on the "used data only" of the students is significantly correlated with their age and year-level. Although the students used data only to attend online classes, they never lost their enthusiasm to accomplish their activities and perform home tasks. It was found out that the second-year college students can adapt to using data only than the first-year college students.

\section{Conclusions}

The majority of the student-respondents are from the Bachelor of Technology and Livelihood Education courses. They are first-year females and fall within 20 years old and below.

All the identified challenges presented to them were verbally described as "Very High Extent." The students' topmost challenges were noise/environmental distractions, technical issues, and slow internet connection. Course expectations and uncertainly about the future were the minor challenges in online learning during the COVID-19 Pandemic.

Since the classes are held via the online platforms, the students are in their respective homes, and the noise/environmental distractions caused by their neighborhood challenge them greatly. Their respective family members challenge them too, especially if the children play for they are living within a small house.

The students living in a rural area were challenged by the means of living of 
their neighborhood such as poultry, piggery, hog rising, and the like that caused a lot of noise/environmental distractions. In contrast, the students attended their online classes amidst this challenge.

The technical issues challenged the students to a great extent. They were not knowledgeable about fixing their computers, laptops, gadget used, and the like. Further, if service providers are not located in their hometown, they need to travel to the city or malls to have their things fixed.

Slow internet connection challenged students greatly because they used data only to attend to their online learning. Some students dropped off their connections while in their online classes. When they tried to reconnect, they usually found it difficult to re-join the class.

From the challenges identified, "staying motivated" is significantly correlated with their "course" and "used data only" with their age and year-level. Although, the overall result shows no significant relationship between the profiles of the respondents and the challenges in online learning, the self-directed attitude of the students toward their studies from the moment they entered college and chose the BTLEd and BSIE courses, has put them into the situation that no matter what happens, they need to embrace the challenges that will come along the way in their journey as students and as individuals. Although the students used data only to attend online classes, they never lost their enthusiasm to accomplish many school activities and perform home tasks. Second-year college students can quickly adapt to using data only in attending to their online learning than first-year college students.

Since the Pandemic is not yet over with the discovery of the OMICRON variant of the COVID-19 spreading worldwide and believed to be highly infectious, the conduct of the ONLINE classes will remain the medium of learning instruction supported with the modular approach in teaching and learning. School administration should devise ways and means to maintain and strengthen quality instruction, which may focus on the strategies to cater to the needs of the students, be it in the basic education, vocational-technical education, tertiary education, or institutions of higher learning.

Further study on the safety and protection of the students and school personnel-teaching, non-teaching, and administrators should be the top priority focusing on the observance of the physical distancing, wearing of face mask, and face-shield (if necessary). Should there be limited face-to-face courses requiring laboratory activities, classrooms should be retrofitted, accommodating only $50 \%$ of the students in a school.

\section{Recommendations}

The college must consider the situations of the students in the conduct of online classes. At the beginning of the school year, there should be an assessment of the students' needs regarding their capability in terms of the internet connection and equipment needed to meet the demands of the online classes. In this case, 
the teachers have baseline information about their students.

Teachers must be ready with the alternative delivery modes of learning that would cater to the needs of students by creating suitable instructional materials such as audio and video recording of their lessons, PowerPoint presentation, e-modules, and the like.

Since the BTLEd and BSIE are skilled courses, students must be allowed to practice their skills through the actual execution of the lessons they need to learn and acquire to prepare them in the future. Proper measures should be strictly enforced when the students are exposed to essential practice skills, since the Pandemic is not yet over, like wearing a face mask, a face shield, and the practice of social distancing.

Students may free themselves from the noise/environmental distractions coming from their family members, neighborhood, and the community. The synchronous and asynchronous approaches can still be used as the delivery modes of instruction during this Pandemic. However, the asynchronous classes may be given more priority since the slow internet connection at home challenges the students. The students may be given a free-webinar lecture on troubleshooting to address the technical issues they experienced in online learning. Quality education should not be compromised. The learning competencies should not be compromised by reviewing and revising the syllabus of instruction which covered the most important competencies.

\section{Conflicts of Interest}

The authors declare no conflicts of interest.

\section{References}

[1] Horton, W. (2006) E-Learning by Design. Pfeiffer, San Francisco.

[2] Sangrà, A., Vlachopoulos, D., Cabrera, N. and Bravo, S. (2011) Towards an Inclusive Definition of e-Learning. eLearning Center UOC (Universitat Oberta de Catalunya), Barcelona..

[3] Raheem, B.R. and Khan, M.A. (2020) The Role of E-Learning in Covid-19 Crisis. International Journal of Creative Research Thoughts, 8, 3135-3138.

[4] Cohen, E. and Nycz, M. (2006) Learning Objects and E-Learning: An Informing Science Perspective. Interdisciplinary Journal of e-Skills and Lifelong Learning, 2, 23-34. https://doi.org/10.28945/399

[5] Oye, N.D., Salleh, M. and Iahad, N.A. (2012) E-Learning Methodologies and Tools. International Journal of Advanced Computer Science and Applications, 3, 48-52.

[6] Cheung, C. and Cable, J. (2017) Eight Principles of Effective Online Teaching: A Decade-Long Lessons Learned in Project Management Education. PM World Journal, 6, 1-16.

[7] Babu, D.G.S. and Sridevi, D.K. (2018) Importance of E-Learning in Higher Education: A Study. International Journal of Research Culture Society, 2, 84-88.

[8] Fellows, R. and Liu, A. (2008) Research Methods for Construction. 3rd Edition, Blackwell Publishing Ltd., Hoboken.

https://www.scirp.org/reference/referencespapers.aspx?referenceid=2665024 
[9] Matthews, B. and Ross, L. (2010) Research Methods. Pearson Longman, London.

[10] Hakim, C. (2000) Research Design: Successful Designs for Social and Economic Research. Oxford University Press, Oxford.

[11] Bryman, A. and Bell, E. (2007) The Ethics of Management Research: An Exploratory Content Analysis. British Journal of Education, 18, 63-77. https://doi.org/10.1111/j.1467-8551.2006.00487.x

[12] Cabual, R.A. (2021) Learning Styles and Preferred Learning Modalities in the New normal. OALib, 8, 1-14.

[13] (2021) Ph Moves up in Mobile Internet Speed Global Rankings. Department of Information and Communication Technology. https://dict.gov.ph/ph-moves-up-in-mobile-internet-speed-global-rankings/

[14] Piaget, J. (1977) The Development of Thought: Equilibrium of Cognitive Structures. Viking as Cited by Constructivism and Online Education by Peter E. Doolittle, Virginia Tech, New York.

[15] Hmelo-Silver, C.E., Golan Duncan, R. and Chinn, C. (2007) Scaffolding and Achievement in Problem-Based and Inquiry Learning: A Response to Kirschner, Sweller, and Clark (2006). Educational Psychologist, 42, 99-107. https://doi.org/10.1080/00461520701263368

[16] Ane, T. and Nepa, T. (2021) Statistical Survey of Students' Performance: Online Education to COVID-19 in Bangladesh. Open Access Library Journal, 8, 1-10.

[17] Paris, S.G. and Turner, J.C. (1994) Situated Motivation. In: Pintrich, P.R., Brown, D.R. and Weinstein, C.E., Eds., Student Motivation, Cognition, and Learning. Essays in Honor of Wilbert J. McKeachie, Lawrence Elbraum, Hillside, 213-237.

[18] Schunk, D.H. and Usher, E.L. (2012) Social Cognitive Theory and Motivation. In: Ryan, R.M., Ed., The Oxford Handbook of Human Motivation, Oxford University Press, Oxford, 13-27. https://doi.org/10.1093/oxfordhb/9780195399820.013.0002

[19] Ryan, R.M. and Deci, E.L. (2000) Self-Determination Theory and the Facilitation of Intrinsic Motivation, Social Development, and Well-Being. American Psychologist, 55, 68-78. https://doi.org/10.1037/0003-066X.55.1.68

[20] Brophy, J. (2010) Motivating Students to Learn. 3rd Edition, Routledge, New York.

[21] Schunk, D.H., Meece, J.L. and Pintrich, P.R. (2014) Motivation in Education: Theory Research and Applications. 94th Edition, Pearson, Boston.

[22] Bekele, T.A. (2010) Motivation and Satisfaction in Internet-Supported Learning Environments: A Review. Educational Technology \& Society, 13, 116-127. 